\title{
The Ameliorative Effect of 23-Hydroxytormentic Acid Isolated from Rubus coreanus on Cisplatin-Induced Nephrotoxicity in Rats
}

\author{
Se-Il SoHN, ${ }^{a}$ Hong-Kun Rim, ${ }^{a, d}$ Yang-Hee KIm, ${ }^{a, d}$ Jung-Hye CHOI, ${ }^{b, c}$ Jae-Hoon PArK, ${ }^{d}$ \\ Hee-Juhn PARK, ${ }^{e}$ Jong-won ChoI, ${ }^{f}$ Soo-dong KIm, ${ }^{g}$ Seo-Young JEOnG, ${ }^{b}$ and Kyung-Tae LeE ${ }^{*}, a, b, d$ \\ ${ }^{a}$ Department of Pharmaceutical Biochemistry, College of Pharmacy, Kyung Hee University; ${ }^{b}$ Department of Life and \\ Nanopharmaceutical Science, College of Pharmacy, Kyung Hee University; ' Department of Oriental Pharmaceutical \\ Science, College of Pharmacy, Kyung Hee University; ${ }^{d}$ Medical Science and Engineering Research Center for Bioreaction \\ to Reactive Oxygen Species, School of Medicine, Kyung Hee University; Seoul 130-701, Republic of Korea: ${ }^{e}$ Department \\ of Botanical Resources, Sangji University; Wonju 220-702, Republic of Korea: ${ }^{f}$ College of Pharmacy, Kyungsung \\ University; Pusan 608-736, Republic of Korea: and ${ }^{g}$ Department of Urology, College of Medicine, Dong-A University; \\ Pusan 602-715, Republic of Korea. Received March 31, 2011; accepted June 6, 2011; published online June 22, 2011
}

Previously, the authors demonstrated that the triterpenoid glycoside niga-ichigoside $\mathrm{F}_{1}\left(\mathrm{NIF}_{1}\right)$ and its aglycone 23-hydroxytormentic acid (23-HTA) isolated from the unripe fruits of Rubus coreanus (Rosaceae) ameliorate cisplatin-induced toxicity in renal epithelial $L L C-P K_{1}$ cells. In the present study, the nephroprotective effects of $\mathrm{NIF}_{1}$ and 23-HTA were investigated in Sprague-Dawley rats with acute renal injury induced by a single intraperitoneal (i.p.) injection of cisplatin $(7 \mathrm{mg} / \mathrm{kg})$. Pretreatment with $23-\mathrm{HTA}(10 \mathrm{mg} / \mathrm{kg} / \mathrm{d}$, per os (p.o.)) significantly reduced cisplatin-induced elevations in blood urea nitrogen (BUN) and serum creatinine level, whereas $\mathrm{NIF}_{1}(10 \mathrm{mg} / \mathrm{kg}$, p.o. $)$ slightly reduced these levels. In addition, pretreatment with 23 -HTA prevented cisplatin-induced hydroxyl radical generation, malondialdehyde (MDA) production, glutathione (GSH) depletion, and cisplatin-induced changes in the activities of oxidant and antioxidant enzymes in rat renal tissues. In addition, histopathological examinations showed that 23-HTA pretreatment reduced cisplatin-induced acute tubular necrosis and histological changes. In contrast, $\mathrm{NIF}_{1}$ was found to have a slight or no influence on cisplatin-induced oxidative enzymes and acute tubular necrosis. Taken together, these results suggest that protective effect of 23-HTA pretreatment on cisplatin-induced renal damage is associated with the attenuation of oxidative stress and the preservation of antioxidant enzymes.

Key words niga-ichigoside $\mathrm{F}_{1}$; 23-hydroxytormentic acid; cisplatin; nephrotoxicity; oxidative stress; antioxidant enzyme

Cisplatin (cis-diaminedichloroplatinum II) is a highly effective antineoplastic DNA alkylating agent that is widely used to treat many cancers, such as, head and neck, ovarian, testicular, mammalian, and cervical cancer. ${ }^{1)}$ However, although higher doses of cisplatin are more effective, many reversible and irreversible side effects including nephrotoxicity, neurotoxicity, bone marrow toxicity, gastrointestinal toxicity, and ototoxicity limit its therapeutic profile. ${ }^{2)}$ The primary targets of cisplatin in the kidney are the proximal straight and distal convoluted tubules, in which it accumulates and promotes cellular damage via multiple mechanisms, such as, oxidative stress, DNA damage, and apoptosis. $^{3-5)}$ Cisplatin nephrotoxicity can present as Fanconi-like syndrome, distal renal tubular acidosis, hypocalcemia, and acute kidney injury, the latter of which occurs in $20-30 \%$ of patients undergoing cisplatin treatment. ${ }^{6)}$

It has been demonstrated that cisplatin induces cell death of renal tubules, which is characterized by reduced glutathione (GSH) levels, and higher blood urea nitrogen (BUN), serum creatinine, and malondialdehyde (MDA) levels, which are suggestive of accelerated peroxidative processes. Furthermore, reactive oxygen species (ROS) are known to cause tissue damage by interacting with various macromolecules, such as, polyunsaturated fatty acids, in the cellular membrane. ROS are generated endogenously in renal cells, and are directly removed by endogenous antioxidants, such as, GSH and superoxide dismutase (SOD). It has been suggested that ROS upregulation is associated with an impaired glomerular filtration rate (GFR). ${ }^{7)}$ On the other hand, antioxidants maintain intracellular reduced GSH concentra- tions, restore cellular defense mechanisms, block lipid peroxidation, and thus, protect real cells against the noxious effects of a wide variety of nephrotoxic agents. ${ }^{8,9)}$ Several studies have suggested that cisplatin induces ROS and reactive nitrogen species (RNS), which both deplete GSH and cause lipid peroxidation. ${ }^{10-12)}$ In particular, the hydroxyl radical is generated by the interaction between DNA and cisplatin, and attacks renal microsomal membranes and causes lipid peroxidation. ${ }^{13)}$ Furthermore, the depletion of renal GSH may also increase MDA levels and the formations of stable proteincisplatin adducts, and decrease the activities of antioxidant enzymes, such as, SOD, catalase (CAT), glutathione reductase (GR), and glutathione peroxidase (GPx). ${ }^{14,15)}$ Cisplatin is also known to increase the activities of the oxidant enzymes, such as aldehyde oxidase (AO) and xanthine oxidase (XO), which are major contributors to oxidant load in renal tissues. ${ }^{16,17)}$

Rubus coreanus (Rosaceae) is a perennial shrub found in southern part of Korea, and its dried unripe fruits have been used for centuries as an herbal medicine, particularly to improve libido. ${ }^{11)}$ In one study undertaken to compare of antioxidant activities of seventy herbs used in Korean traditional medicine, Rubus coreanus demonstrated potent antioxidant activities during three different antioxidant assays. ${ }^{19)}$ In fact, several saponins, such as, the $19 \alpha$-hydroxyursane-type triterpenoids and their glycosides isolated from Rubus sp. have been shown to act as antioxidants. ${ }^{20)}$

In a previous study, we found that the triterpenoid glycoside niga-ichigoside $\mathrm{F}_{1}\left(\mathrm{NIF}_{1}\right)$ and its aglycone 23-hydroxytormentic acid (23-HTA), isolated from the unripe fruits of 
Rubus coreanus, had antinociceptive, anti-inflammatory, anti-gastropathic, and anti-rheumatic effects in animal models. ${ }^{21,22)}$ It is of note that both compounds acted as antioxidants in a carrageenan-induced edema model and in an ethanol-sodium salicylate-induced gastropathy model. Fur-

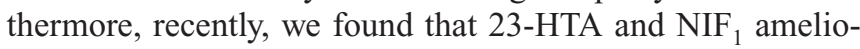
rate cisplatin-induced toxicity by modulating the expressions of antioxidant enzymes via Nrf2 activation in renal epithelial LLC-PK $_{1}$ cells. $^{23)}$ These observations encouraged us to investigate the protective effects of 23 -HTA and NIF $_{1}$ on cisplatin-induced nephropathy in a rat model, and the possible mechanisms underlying these effects.

\section{MATERIALS AND METHODS}

Materials 23-HTA and $\mathrm{NIF}_{1}$ (Fig. 1A) used in this study were isolated from the roots of Rubus coreanus as previously described. ${ }^{21)}$ Both compounds were subjected to LC-MS and found to be $>96 \%$ pure. Cisplatin, epinephrine, GSH, oxidized GSH (GSSG), 2-vinylpyridine, 5,5' -dithiobis-2-nitrobenzoic acid (DTNB), and deferoxamine (DFO) were purchased from Sigma Chemical Co. (St. Louis, MO, U.S.A.). BUN and serum creatinine kits were purchased from Asan Pharm. (Seoul, Republic of Korea) and Sigma, respectively. GR and GPx kits were purchased from Cayman Chemical Co. (Ann Arbor, MI, U.S.A.).

Animals and Experimental Design All procedures were approved by the Institutional Animal Care and Use Committee of Kyung Hee University (\#KHP-2008-08-14). Male Sprague-Dawley (SD) rats weighing 190-210 g were purchased from Orient Bio (Gyeonggi, Republic of Korea). Rats were housed 4/cage and fed standard laboratory chow under a $12 \mathrm{~h}$ dark/light cycles in a controlled laboratory environment $\left(20 \pm 2{ }^{\circ} \mathrm{C}\right.$; $\left.\mathrm{RH} 40-60 \%\right)$ for two weeks. Twentyfour hours before experiments animals were allowed water only. To exclude diurnal enzyme activity variations, animals were sacrificed between 10:00-12:00 a.m. Animals were allocated to five groups ( $n=10 /$ group): the vehicle-treated control group, the cisplatin alone treated group, the 23-HTA plus cisplatin group, the $\mathrm{NIF}_{1}$ plus cisplatin group, and the DFO plus cisplatin group. Control animals were administered physiological saline containing $0.1 \%$ of tween 80 via same routes as 23-HTA or $\mathrm{NIF}_{1}$. Cisplatin was injected intraperitoneally (i.p.) at $7 \mathrm{mg} / \mathrm{kg}$ body weight. $23-\mathrm{HTA}$ or $\mathrm{NIF}_{1}$ were administered at $10 \mathrm{mg} / \mathrm{kg} / \mathrm{d}$ p.o. daily for consecutive $14 \mathrm{~d}$ tarting $1 \mathrm{~d}$ before cisplatin administration. DFO was administered orally at $250 \mathrm{mg} / \mathrm{kg}$ daily for $14 \mathrm{~d}$ before the cisplatin injection at a dose of $7 \mathrm{mg} / \mathrm{kg}$ body weight.

Biochemical Determination Rats were sacrificed $4 \mathrm{~d}$ after administration of cisplatin. BUN, serum creatinine, and hydroxyl radical content were determined by centrifuging blood for $10 \mathrm{~min}$ at $3000 \mathrm{rpm}$. BUN and serum creatinine were measured using commercial kits according to the manufacturer's instructions and results are expressed as mg/dl. Hydroxyl radical levels were measured using the method of Kobatake et al. ${ }^{24)}$ The kidneys of rats were removed surgically, washed with physiological saline solution and cleared of fatty tissue. Tissues were homogenized and prepared for assays as described previously. ${ }^{25)}$ Upper clear portions of tissue homogenates were used for measurements. Protein concentrations were determined using Bio-Rad protein assay
A

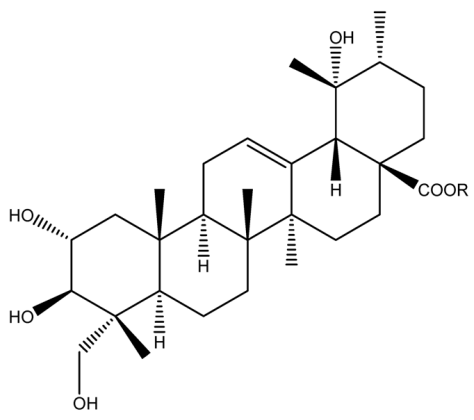

23-Hydroxytormentic acid: $\mathbf{R}=\mathbf{H}$ Niga-ichigoside $F_{1}: R=\beta$-D-glucopyranosyl

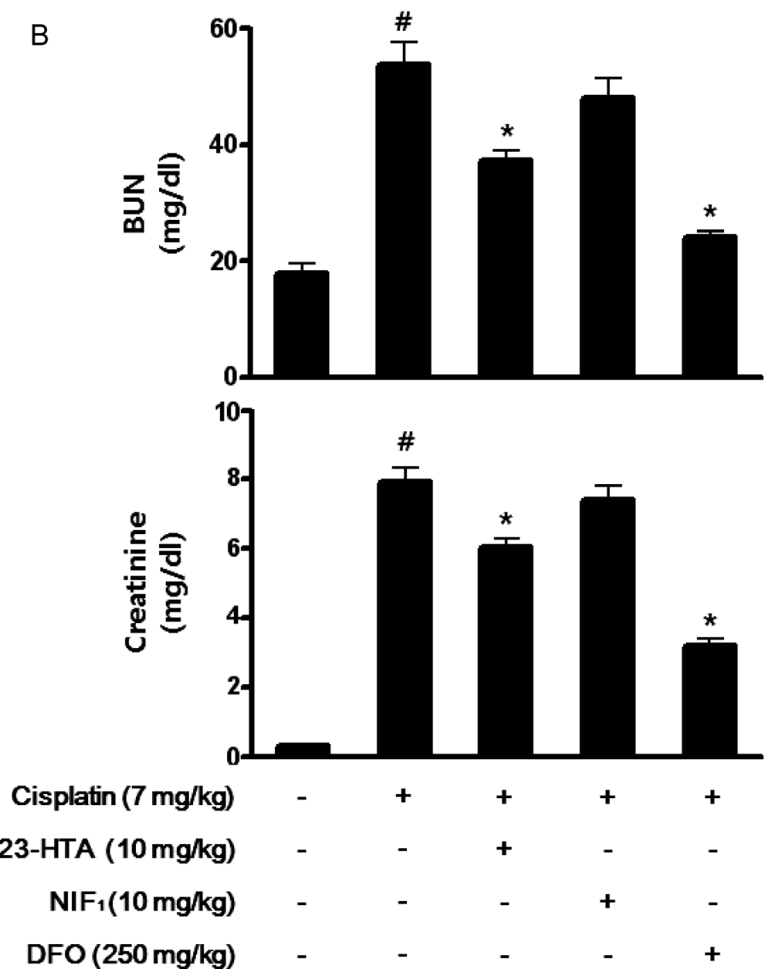

Fig. 1. Effects of 23-HTA and $\mathrm{NIF}_{1}$ on BUN and Serum Creatinine Levels in a Rat Model of Cisplatin-Induced Acute Renal Injury

(A) Chemical structures of 23-HTA $(\mathrm{R}=\mathrm{H})$ and $\mathrm{NIF}_{1}(\mathrm{R}=\mathrm{Glc})$ isolated from Rubus coreanus. (B) Acute renal injury was induced by injecting cisplatin ( $7 \mathrm{mg} / \mathrm{kg}$, i.p.). Rats were treated with $23-\mathrm{HTA}(10 \mathrm{mg} / \mathrm{kg})$ or $\mathrm{NIF}_{1}(10 \mathrm{mg} / \mathrm{kg})$ daily for $14 \mathrm{~d}$ prior to being injected with cisplatin $(7 \mathrm{mg} / \mathrm{kg}$, i.p.). Control rats were administered physiological saline containing $0.1 \%$ tween 80 . BUN and serum creatinine levels were measured $4 \mathrm{~d}$ after cisplatin administration. DFO (an antioxidant) was used as a positive control. The data presented are mean \pm S.D., $n=10$ in each group. $\# p<0.05 v s$. vehicle-treated control group; $* p<0.05 v s$. cisplatin alone treated group.

reagent (Bio-Rad Laboratories Inc., CA, U.S.A.). MDA, GSH levels, AO, XO, SOD, CAT, GR, and GPx enzymes activities were measured in supernatants. MDA levels were measured using the thiobarbituric acid reactive substances (TBARS) method. ${ }^{13)}$ GSH was assayed using an enzymatic recycling procedure adapted for a microplate reader. ${ }^{26)} \mathrm{AO}$ activity was determined by measuring 2-pyridone formation at $300 \mathrm{~nm}^{27}$ XO activity was determined by measuring uric acid formation from xanthine at $295 \mathrm{~nm} .^{28)}$ SOD activity was determined as described by Misra and Fridovich ${ }^{29)}$ at room temperature. CAT activity was determined by measuring hydrogen peroxide $\left(\mathrm{H}_{2} \mathrm{O}_{2}\right)$ absorbance decreases at $\left.240 \mathrm{~nm},{ }^{30}\right)$ and GR and GPx activities were measured by following 
changes in reduced nicotinamide adenine dinucleotide phosphate (NADPH) absorbance at $340 \mathrm{~nm}$ using Cayman kits. ${ }^{31}$ ) $\gamma$-Glutamyl transferase $(\gamma$-GT) and $\gamma$-glutamylcysteine synthetase $(\gamma$-GCS) activities were determined using the methods described by Habig et al. and Meister and Richman, respectively. ${ }^{32,33)}$

Histopathological Examination of Renal Tissues Left kidneys were fixed in 10\% formalin, dehydrated in an alcohol series, and embedded in paraffin. Sections $(4 \mu \mathrm{m})$ were stained with H\&E and examined under a light microscope by a pathologist unaware of the treatment protocol.

Statistical Analysis Data are reported as means \pm S.D. Statistical analysis was performed by analysis of variance (ANOVA) followed by Dunnett's multiple comparison test. $p$ values of $<0.05$ were considered statistically significant.

\section{RESULTS}

Effects of 23-HTA and NIF $_{1}$ on Cisplatin-Induced Renal Injury in Rats In a previous study, we found that the aglycone 23-HTA and its glycoside $\mathrm{NIF}_{1}$ protected against cisplatin-induced cytotoxicity and against increases in intracellular oxidant status in $\mathrm{LLC}^{-\mathrm{PK}_{1}}$ cells. $^{23)}$ We further explored the in vivo efficacies of 23-HTA or $\mathrm{NIF}_{1}$ in terms of preventing cisplatin-induced acute renal injury in rats by measuring BUN and serum creatinine levels. In this study, 23-HTA and $\mathrm{NIF}_{1}$ were administered to rats at $10 \mathrm{mg} / \mathrm{kg}$ (per os (p.o.)) based on our previous findings. ${ }^{21)}$ No significant toxic effects were observed even at dose of $30 \mathrm{mg} / \mathrm{kg}$ in this rat model. As shown in Fig. 1B, a single dose of cisplatin $(7 \mathrm{mg} / \mathrm{kg}$, i.p.) significantly elevated BUN and serum creatinine concentrations (by 3.0- and 24.9-fold, respectively, $p<0.05)$ as compared with vehicle-treated control rats. Pretreatment with $23-\mathrm{HTA}(10 \mathrm{mg} / \mathrm{kg}$, p.o.) for $14 \mathrm{~d}$ prior to cisplatin was found to significantly reduce BUN by $30.6 \%$ and serum creatinine levels by $23.6 \%$ as compared with cisplatin alone treated rats, whereas pretreatment with $\mathrm{NIF}_{1}$ alone only caused marginal reductions. Furthermore, pretreatment with DFO $(250 \mathrm{mg} / \mathrm{kg}$, p.o.; a positive control) significantly prevented cisplatin-induced nephrotoxicity. ${ }^{34,35)}$

Effects of 23-HTA and NIF $_{1}$ on Hydroxyl Radical, MDA, and GSH Levels in Cisplatin-Treated Rats To determine whether oxidative stress was involved in the nephroprotection afforded by $23-\mathrm{HTA}$ or $\mathrm{NIF}_{1}$, we investigated hydroxyl radical levels in serum and lipid peroxidation and GSH levels in kidney tissues. The administration of cisplatin $(7 \mathrm{mg} / \mathrm{kg}$, i.p.) significantly increased hydroxyl radical levels in serum and MDA levels in kidney tissues as compared with vehicle-treated control rats $(6.52 \pm 0.36,3.18 \pm 0.6$ vs. $2.36 \pm$ $0.17,1.31 \pm 0.13$, respectively, $p<0.05$ ) (Fig. 2). Furthermore, pretreatment with 23-HTA prior to cisplatin significantly reduced hydroxyl radical and MDA levels versus cisplatin alone treated rats by $41.3 \%$ and $20.4 \%$, respectively. On the other hand, pretreatment with $\mathrm{NIF}_{1}$ elicited only slight reductions. GSH is an important endogenous antioxidant that protects cells and tissues from oxidative stress. Therefore, we investigated the effects of 23-HTA and $\mathrm{NIF}_{1}$ on GSH levels in cisplatin alone treated rat kidneys. Cisplatin $(7 \mathrm{mg} / \mathrm{kg}$, i.p.) significantly reduced mean GSH contents $(0.28 \pm 0.04$ vs. $0.42 \pm 0.07, p<0.05)$ in kidney tissues, and pretreatment with 23-HTA markedly inhibited this reduction (Fig. 2). In addi-

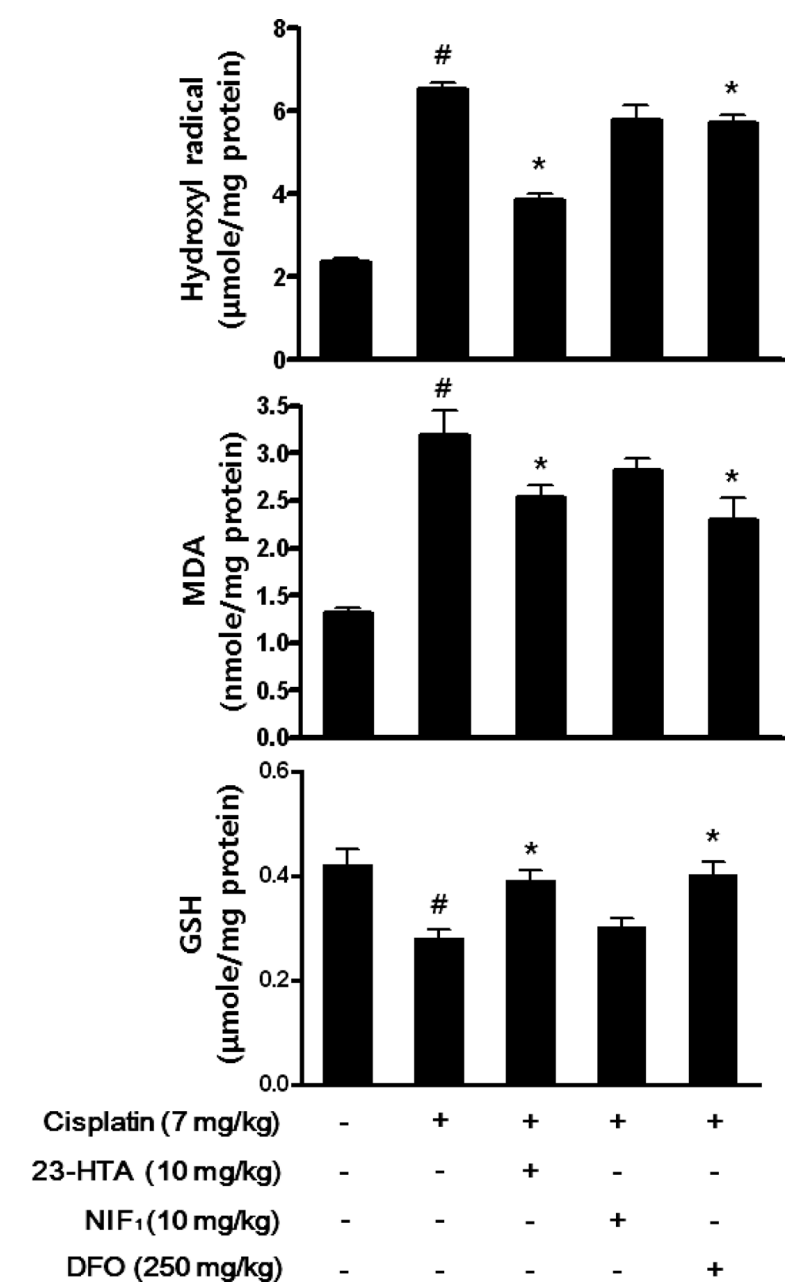

Fig. 2. Effects of 23-HTA and $\mathrm{NIF}_{1}$ on Oxidative Stress Caused by Cisplatin-Induced Acute Renal Injury

Rats were sacrificed $4 \mathrm{~d}$ after cisplatin administration. Blood was collected to determine its hydroxyl radical content. Kidneys were excised and homogenized to measure MDA (due to lipid peroxidation) and GSH levels in renal tissues. DFO was used as a positive control. The data presented are mean \pm S.D., $n=10$ in each group. $\# p<0.05 v s$. the vehicle-treated control group; $* p<0.05 v s$. the cisplatin alone treated group.

tion, we investigated the activities of $\gamma$-GCS and $\gamma$-GT, which are required for cellular GSH formation and degradation, respectively. As shown in Table 1, cisplatin reduced the activity of renal $\gamma$-GCS $(73.2 \pm 8.7$ vs. $110.8 \pm 9.6, p<0.05)$ and increased the activity of renal $\gamma$-GT $(284.6 \pm 49.5 v s$. 21.7 $\pm 5.4, \quad p<0.05)$. However, these cisplatin-induced changes were markedly restored by 23 -HTA or DFO (the positive control), but not by $\mathrm{NIF}_{1}$.

Effects of 23-HTA and NIF $_{1}$ on Oxidant and Antioxidant Enzyme Activities in Cisplatin-Treated Rats It has been reported that cisplatin-induced oxidative stress is caused by an imbalance between the production and removal of ROS. ${ }^{10,11)}$ Therefore, we investigated whether 23-HTA or $\mathrm{NIF}_{1}$ modulate cisplatin-induced oxidative statuses by measuring the activities of oxidant and antioxidant enzymes. Cisplatin was found to significantly increase the activity of $\mathrm{AO}$ $(16.6 \pm 0.58 v s .13 .3 \pm 0.79, p<0.05)$, but not that of $\mathrm{XO}$, in kidney tissues (Table 2), and pretreatment with 23-HTA or $\mathrm{NIF}_{1}$ significantly reduced AO activity after cisplatin treatment by $10.2 \%$ and $8.4 \%$, respectively. In addition, the activities of SOD, CAT, GR, and GPx were found to be significantly reduced in cisplatin alone treated rats (by $67.7 \%$, 
$54.2 \%, 41.0 \%, 55.1 \%$, respectively, $p<0.05)$ as compared with vehicle-treated control rats (Table 2). In contrast, pretreatment with $23-\mathrm{HTA}$ or $\mathrm{NIF}_{1}$ significantly prevented these reductions. Furthermore, 23-HTA was found to have greater protective effects than $\mathrm{NIF}_{1}$ on the activities of oxidant and antioxidant enzymes in our rat model. The above results suggest that 23-HTA significantly attenuates oxidative stress by suppressing the oxidant enzyme AO and by augmenting the activities of antioxidant enzymes, such as, SOD, CAT, GR, and GPx.

Effects of 23-HTA and NIF $_{1}$ on Renal Tissue Histology Cisplatin was found to induce acute tubular necrosis, tubular dilatation, vacuolar degeneration, epithelial desquamation, and intraluminal cast formation in proximal convoluted tubules (Fig. 3B). However, animals administered 23-HTA or DFO before cisplatin showed only minimal changes (Figs. $3 \mathrm{C}, \mathrm{D})$, but $\mathrm{NIF}_{1}$ had little effect on cisplatin-induced changes (Fig. 3E).

\section{DISCUSSION}

Rubus coreanus is used in traditional Korean medicine to improve kidney function, and is known to have substantial antioxidant activity. ${ }^{19)}$ We previously isolated $\mathrm{NIF}_{1}$ from the butanol extract of Rubus coreanus and hydrolyzed it to produce the aglycon 23-HTA, ${ }^{21)}$ because aglycones are more active than their corresponding glycosides, though not always. ${ }^{36)}$ In the present study, we compared the protective effects of the triterpenoid glycoside $\mathrm{NIF}_{1}$ and its aglycone 23HTA in rats exposed to acute cisplatin-induced nephrotoxicity by measuring improvements in biochemical parameters and assessing renal tissue damage amelioration observed by histopathological examination.

Since the nephrotoxicity of cisplatin limits its usefulness, it is critical that the mechanisms involved be elucidated and that agents capable of protecting renal tubules from the ef-

Table 1. Effects of 23-HTA and $\mathrm{NIF}_{1}$ on $\gamma$-GCS and $\gamma$-GT Activities in Cisplatin-Induced Acute Renal Injury

\begin{tabular}{|c|c|c|}
\hline Treatment & $\gamma-\mathrm{GCS}^{a)}$ & $\gamma-\mathrm{GT}^{b)}$ \\
\hline Control & $110.8 \pm 9.6$ & $21.7 \pm 5.4$ \\
\hline Cisplatin & $73.2 \pm 8.7^{\#}$ & $284.6 \pm 49.5^{\#}$ \\
\hline Cisplatin + 23-HTA & $86.9 \pm 6.2$ & $200.6 \pm 11.5^{*}$ \\
\hline$+\mathrm{NIF}_{1}$ & $80.5 \pm 8.9$ & $260.4 \pm 37.6$ \\
\hline$+\mathrm{DFO}$ & $96.3 \pm 7.3^{*}$ & $99.5 \pm 18.4^{*}$ \\
\hline
\end{tabular}

a) $\mathrm{Pi} \mathrm{nmol} / \mathrm{min} / \mathrm{mg}$ protein, $b$ ) unit $/ \mathrm{mg}$ protein. The values are expressed as mean \pm S.D., $n=10$ in each group. $\# p<0.05$ vs. control group; $* p<0.05$ vs. cisplatin treated group; the significances of differences between treatment groups were evaluated using ANOVA followed by Dunnett's test. fects of cisplatin are identified. Cisplatin-induced nephrotoxicity results in severe nephropathy involving acute renal failure, which are associated with the loss of renal functions, including severe reductions in glomerular filtration and creatinine clearance, and increased levels of BUN and serum creatinine. ${ }^{37-39)}$ Levels of BUN and serum creatinine correlate well with renal function, and thus, are useful for evaluating kidney function. This study shows that 23-HTA significantly attenuates cisplatin-induced nephrotoxicity by observing the suppression of BUN and serum creatinine levels.

Recent evidence suggests that cisplatin-induced nephrotoxicity is caused by oxidative stress and increased levels of the superoxide anion, hydrogen peroxide, and hydroxyl radicals caused by the increased activities of NADPH oxidase, xanthine oxidase, and adenosine deaminase. ${ }^{40,41)}$ Increased ROS production decreases the activities of the antioxidant enzymes (CAT, SOD, and GPx), depletes GSH and protein thiols, and enhances lipid peroxidation in renal tissue. ${ }^{42)}$ In

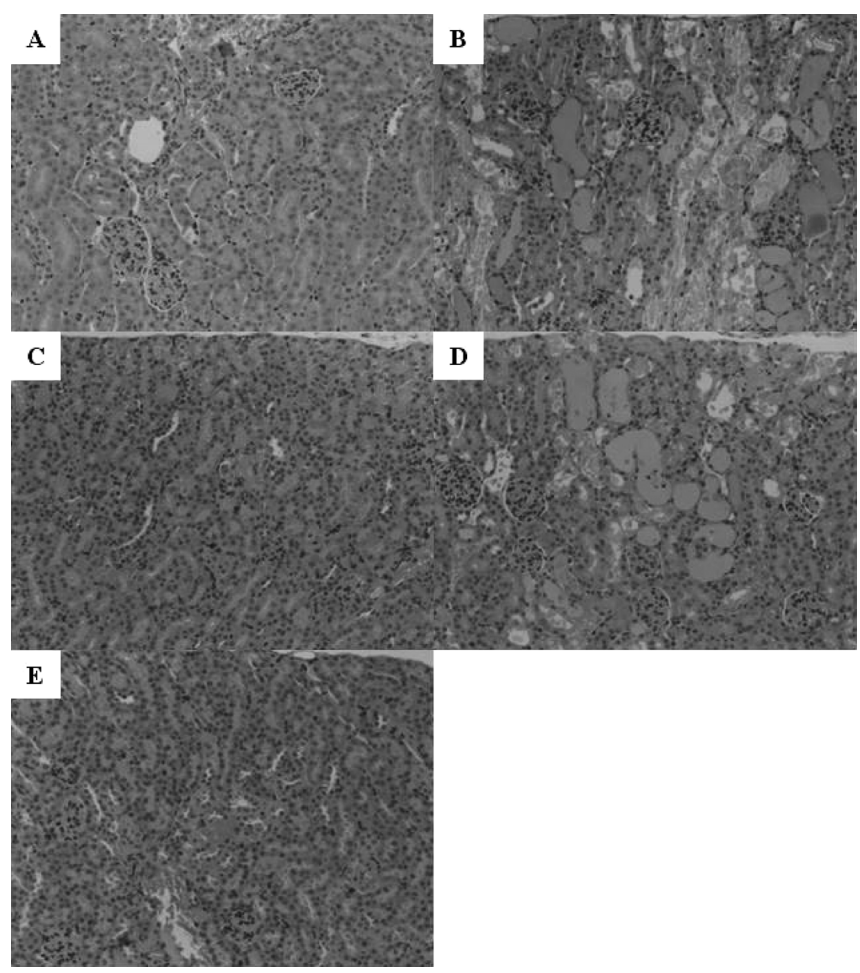

Fig. 3. Effects of 23-HTA and $\mathrm{NIF}_{1}$ on Renal Tissue Histology in Cisplatin-Treated Rats

Animals were sacrificed at $4 \mathrm{~d}$ after cisplatin injection. Renal tissues were stained with H\&E $(100 \times)$. (A) The vehicle-treated control group; (B) the cisplatin $(7 \mathrm{mg} / \mathrm{kg}$, i.p.) alone treated group; (C) the $23-\mathrm{HTA}(10 \mathrm{mg} / \mathrm{kg}$, p.o.) plus cisplatin treated group; (D) the $\mathrm{NIF}_{1}(10 \mathrm{mg} / \mathrm{kg}$, p.o. $)$ plus cisplatin treated group; and (E) the DFO $(250 \mathrm{mg} / \mathrm{kg}$, p.o.) plus cisplatin treated group.

Table 2. Effects of 23-HTA and $\mathrm{NIF}_{1}$ on Activities of AO, XO, and Antioxidant Enzymes in Cisplatin-Treated Rats

\begin{tabular}{|c|c|c|c|c|c|c|}
\hline Treatment & $\mathrm{AO}^{a)}$ & $\mathrm{XO}^{b)}$ & $\mathrm{SOD}^{c)}$ & $\mathrm{CAT}^{d)}$ & $\mathrm{GR}^{e)}$ & $\mathrm{GPx}^{e)}$ \\
\hline Control & $13.3 \pm 0.79$ & $0.86 \pm 0.09$ & $3.1 \pm 0.29$ & $199.2 \pm 4.9$ & $290.2 \pm 10.5$ & $246.3 \pm 12.8$ \\
\hline Cisplatin & $16.6 \pm 0.58^{\#}$ & $0.93 \pm 0.10$ & $1.0 \pm 0.17^{\#}$ & $91.2 \pm 5.3^{\#}$ & $130.0 \pm 9.4^{\#}$ & $145.2 \pm 13.3^{\#}$ \\
\hline Cisplatin + 23-HTA & $14.9 \pm 0.63^{*}$ & $0.88 \pm 0.11$ & $2.8 \pm 0.19^{*}$ & $169.2 \pm 4.2 *$ & $230.6 \pm 21.7 *$ & $210.6 \pm 13.0^{*}$ \\
\hline$+\mathrm{NIF}_{1}$ & $15.2 \pm 0.53 *$ & $0.90 \pm 0.27$ & $1.9 \pm 0.21 *$ & $110.9 \pm 8.2 *$ & $160.4 \pm 18.3^{*}$ & $164.5 \pm 10.3 *$ \\
\hline$+\mathrm{DFO}$ & $14.0 \pm 0.29$ & $0.83 \pm 0.13$ & $1.5 \pm 0.26^{*}$ & $98.7 \pm 4.2 *$ & $157.3 \pm 10.0 *$ & $156.5 \pm 12.0 *$ \\
\hline
\end{tabular}

a) Uric acid nmol $/ \mathrm{min} / \mathrm{mg}$ protein, b) 2-pyridone $\mathrm{nmol} / \mathrm{min} / \mathrm{mg}$ protein, $c$ ) unit $/ \mathrm{mg}$ protein, $d$ ) decreased $\mathrm{H}_{2} \mathrm{O}_{2} \mathrm{nmol} / \mathrm{min} / \mathrm{mg} \mathrm{protein}, e$ ) oxidized NADPH nmol $/ \mathrm{min} / \mathrm{mg} \mathrm{pro}$ tein. The values are expressed as mean \pm S.D., $n=10$ in each group. $\# p<0.05 v s$. control group; $* p<0.05 v s$. cisplatin treated group; the significances of differences between treatment groups were evaluated using ANOVA followed by Dunnett's test. 
addition, cisplatin-induced nephrotoxicity is characterized by the destruction of intracellular organelles, cellular necrosis, loss of microvilli, alterations in lysosome numbers and sizes, and mitochondrial vacuolization, which are followed by GSH depletion, lipid peroxidation, and mitochondrial damage. ${ }^{1,6)}$ In the present study, cisplatin was found to significantly increase the levels of hydroxyl radical in serum and of MDA in kidney tissues. Furthermore, cisplatin was also found to markedly decrease GSH levels and the activity of $\gamma$-GCS, whereas $\gamma$-GT activity was reduced, which are required for cellular GSH formation or degradation. These findings regarding the effects of cisplatin are consistent with our previous findings that cisplatin induces lipid peroxidation, glutathione depletion, and ROS production in $\mathrm{LLC}_{-} \mathrm{PK}_{1}$ renal epithelial cells. $^{23)}$ These observations suggested that cisplatin causes renal tissue damage by inducing oxidative stress. Furthermore, the present study shows that 23-HTA pretreatment prevents cisplatin-induced redox status changes.

ROS are generated under normal cellular conditions and are immediately detoxified by endogenous antioxidants, like GSH, CAT, and SOD. However, the excessive ROS accumulations induced by cisplatin cause antioxidant status imbalance and lead to lipid peroxidation and GSH depletion. ${ }^{43,44)}$ The present study shows that 23-HTA significantly inhibits cisplatin-induced increases in the activities of $\mathrm{AO}$ and $\mathrm{XO}$. Furthermore, increased XO activity is an important contributor to renal oxidant loading, because it is mainly responsible for superoxide radical production in vivo. ${ }^{45)}$ In the present study, the activities of SOD, CAT, GR, and GPx were found to be lower in the kidneys of rats treated with cisplatin. In particular, the selenium containing enzyme GPx, scavenges hydroperoxides and lipid peroxides, and thus, protects cells against ROS. It is evident from the present study that 23HTA pretreatment restored cisplatin induced reductions in SOD, CAT, GR, and GPx activities, indicating that both 23HTA and NIF $_{1}$ significantly prevented cisplatin-induced changes in oxidant and antioxidant enzyme activities in rat renal tissues. Furthermore, the aglycone 23-HTA was found to be more potent than $\mathrm{NIF}_{1}$. $\mathrm{NIF}_{1}$ slightly reduced cisplatininduced increases in BUN, serum creatinine, hydroxyl radical, and MDA levels and GSH depletion. These observations suggest that 23-HTA is the active species that induces the observed nephroprotective effects, and that the glycoside $\mathrm{NIF}_{1}$ becomes effective after it has been converted into 23-HTA when administered orally, possibly in part through enzymatic hydrolysis in the gastrointestinal tract or other biosystems. Since glycoside NIF $_{1}$ showed the either mild or significant nephroprotective efficacy in some in vivo and in vitro assay systems, to investigate the exact mechanism of action of $\mathrm{NIF}_{1}$, we need a further study to analyze plasma concentrations of 23-HTA and NIF $_{1}$ after oral administration in animal systems. In view of the finding that 23-HTA inhibited cisplatin-induced redox status changes, reduced the activities of oxidant enzymes, and increased the activities of antioxidant enzymes, it would appear that the protective effects of 23HTA against cisplatin are due to its antioxidant effects. These findings suggest that 23-HTA inhibits ROS generation by modulating the activities of redox enzymes.

The focus of our research is to identify antioxidants from natural sources that are able to ameliorate cisplatin-induced nephrotoxicity, because these natural antioxidants are likely to be safer than synthetic antioxidants. ${ }^{46)}$ Several antioxidants have been explored in this context, for example, natural selenium-based antioxidants, like ebselen, have been reported to suppress cisplatin-induced oxidative stress in membranes and to prevent GSH depletion by cisplatin in rats. ${ }^{47,48)}$ Furthermore, vitamin $\mathrm{C}$ and $\alpha$-tocopherol (both well-known antioxidants), and superoxidase dismutase overexpression have been reported to ameliorate cisplatin-induced oxidative stress, ${ }^{49-51)}$ which suggests that they protect against cisplatin-induced renal epithelial cell injury. ${ }^{52)}$

In addition to ROS, cisplatin administration causes nuclear factor-kappa B (NF- $\kappa$ B) activation and subsequent inflammatory reactions that cause renal injury. ${ }^{53,54)}$ The upregulation of tumor necrosis factor-alpha (TNF- $\alpha$ ) is known to be an important step in the activation of the NF- $\kappa \mathrm{B}$ signaling pathway. ${ }^{55)}$ Previous studies have shown that agents which inhibit TNF- $\alpha$ production and NF- $\kappa \mathrm{B}$ activation effectively ameliorate cisplatin nephrotoxicity. ${ }^{53,54)}$ In addition, TNF- $\alpha$ knockout mice sustained less renal injury than wild type mice and were found to have markedly higher survival rates following cisplatin injection. ${ }^{56}$ Furthermore, levels of inflammatory cytokines, such as, interleukin-1 betta (IL-1 $\beta$ ) and IL-6, were found to be markedly upregulated under conditions of cisplatin-induced nephrotoxicity, and this increase was found to be associated with an influx of neutrophils and monocytes, which caused toxic acute renal failure. ${ }^{57,58)}$ In our previous studies, we have also described the anti-inflammatory activity of $23-\mathrm{HTA}^{21,22)}$; however, further study is needed to determine whether the protective effect of 23-HTA against cisplatin is due to its ability to inhibit the activation of the NF- $\kappa \mathrm{B}$ signaling pathway, which promotes the transcriptions of NADPH oxidase, TNF- $\alpha$, and iNOS. ${ }^{59)}$

The results of the present study indicate that 23-HTA effectively protects rat kidney tissues against cisplatin-induced acute nephrotoxicity, which suggests that the antioxidant activities of 23-HTA are primarily responsible for the nephroprotective effect of 23-HTA. The findings of the present study indicate that 23-HTA is potential therapeutic candidate for the prevention of renal injury and dysfunction which is a major and dose-limiting problem during cisplatin therapy.

Conflict of Interest The authors have no conflict of interest to declare.

Acknowledgement This study was supported by a Grant from the Korea Healthcare Technology R\&D Project, Ministry for Health, Welfare and Family Affairs, Republic of Korea (A090487).

\section{REFERENCES}

1) Delord J. P., Puozzo C., Lefresne F., Bugat R., Anticancer Res., 29, 553-560 (2009).

2) Lynch E. D., Gu R., Pierce C., Kil J., Hear Res., 201, 81-89 (2005).

3) Schaaf G. J., Maas R. F., de Groene E. M., Fink-Gremmels J., Free Radic. Res., 36, 835-843 (2002).

4) Cummings B. S., Schnellmann R. G., J. Pharmacol. Exp. Ther, 302, 8-17 (2002)

5) Xiao T., Choudhary S., Zhang N., Ansari N. H., Salahudeen A., J. Toxicol. Environ. Health, 66, 469-479 (2003).

6) Yao X., Panichpisal K., Kurtzman N., Nugent K., Am. J. Med. Sci., 334, 115-124 (2007).

7) Pedraza-Chaverrí J., Maldonado P. D., Medina-Campos O. N., Olivares- 
Corichi I. M., Granados-Silvestre M. A., Hernández-Pando R., IbarraRubio M. E., Free Radic. Biol. Med., 29, 602-611 (2000).

8) Gilgun-Sherki Y., Melamed E., Offen D., Neuropharmacology, 40, 959-975 (2001)

9) Wu G., Fang Y. Z., Yang S., Lupton J. R., Turner N. D., J. Nutr., 134, 489-492 (2004).

10) Kuhlmann M. K., Burkhardt G., Köhler H., Nephrol. Dial. Transplant., 12, 2478-2480 (1997).

11) Masuda H., Tanaka T., Takahama U., Biochem. Biophys. Res. Commun., 203, 1175-1180 (1994)

12) Chirino Y. I., Pedraza-Chaverri J., Exp. Toxicol. Pathol., 61, 223-242 (2009).

13) Dahle L. K., Hill E. G., Holman R. T., Arch. Biochem. Biophys., 98, 253-261 (1962).

14) Mistry P., Merazga Y., Spargo D. J., Riley P. A., McBrien D. C., Cancer Chemother. Pharmacol., 28, 277-282 (1991).

15) Zhang J. G., Lindup W. E., Biochem. Pharmacol., 45, 2215-2222 (1993).

16) McCord J. M., Roy R. S., Schaffer S. W., Adv. Myocardiol., 5, 183189 (1985).

17) Garattini E., Fratelli M., Terao M., Cell. Mol. Life Sci., 65, 10191048 (2008).

18) Oh M. S., Yang W. M., Chang M. S., Park W., Kim R., Lee H. K., Kim W. N., Park S. K., J. Ethnopharmacol., 114, 463-467 (2007).

19) Ko S. H., Choi S. W., Ye S. K., Yoo S., Kim H. S., Chung M. H., Nutr. Res. Pract., 2, 143-151 (2008).

20) Jung H.-J., Nam J.-H., Lee K.-T., Lee Y.-S., Choi J., Kim W.-B., Chung W. Y., Park K. K., Park H.-J., Nat. Prod. Sci., 13, 33-39 (2007).

21) Choi J., Lee K. T., Ha J., Yun S. Y., Ko C. D., Jung H. J., Park H. J., Biol. Pharm. Bull., 26, 1436-1441 (2003).

22) Nam N. H., Mini Rev. Med. Chem., 6, 945-951 (2006).

23) Kim Y. H., Choi J. H., Rim H. K., Kang H. J., Chang S. G., Park J. H., Park H. J., Choi J. W., Kim S. D., Lee K. T., Biol. Pharm. Bull., 34, 906-911 (2011)

24) Park C. H., Jeong S. J., Lee H. J., Lee E. O., Bae H., Lee M. H., Kim S. H., Jung H. J., Ahn K. S., Kim S. H., Phytother. Res., 24, 17001709 (2010).

25) Kavutcu M., Canbolat O., Oztürk S., Olcay E., Ulutepe S., Ekinci C., Gökhun I. H., Durak I., Nephron, 72, 269-274 (1996).

26) Eyer P., Podhradský D., Anal. Biochem., 153, 57-66 (1986).

27) Rajagopalan K. V., Handler P., Palmer G., Beinert H., J. Biol. Chem., 243, 3797-3806 (1968).

28) Hashimoto S., Anal. Biochem., 62, 426-435 (1974).

29) Misra H. P., Fridovich I., J. Biol. Chem., 247, 3170-3175 (1972).

30) Aebi H., Methods Enzymol., 105, 121-126 (1984).

31) Paglia D. E., Valentine W. N., J. Lab. Clin. Med., 70, 158-169 (1967).

32) Habig W. H., Pabst M. J., Jakoby W. B., J. Biol. Chem., 249, 71307139 (1974).

33) Meister A., Richman P. G., J. Biol. Chem., 250, 1422-1426 (1975).

34) Baliga R., Zhang Z., Baliga M., Ueda N., Shah S. V., Kidney Int., 53, 394-401 (1998).
35) Kadikoylu G., Bolaman Z., Demir S., Balkaya M., Akalin N., Enli Y., Hum. Exp. Toxicol., 23, 29-34 (2004)

36) Caballero-George C., Vanderheyden P. M., Okamoto Y., Masaki T., Mbwambo Z., Apers S., Gupta M. P., Pieters L., Vauquelin G., Vlietinck A., Phytother. Res., 18, 729-736 (2004)

37) Evenepoel P., Best Pract. Res. Clin. Anaesthesiol., 18, 37-52 (2004).

38) Kang D. G., Lee A. S., Mun Y. J., Woo W. H., Kim Y. C., Sohn E. J., Moon M. K., Lee H. S., Biol. Pharm. Bull., 27, 366-370 (2004).

39) Lameire N., Van Biesen W., Vanholder R., Lancet, 365, 417-430 (2005).

40) Gulec M., Iraz M., Yilmaz H. R., Ozyurt H., Temel I., Toxicol. Ind. Health, 22, 125-130 (2006).

41) Chirino Y. I., Sánchez-González D. J., Martínez-Martínez C. M., Cruz C., Pedraza-Chaverri J., Toxicology, 245, 18-23 (2008).

42) Ali B. H., Al Moundhri M. S., Tag Eldin M. T., Nemmar A., Tanira M. O., Fundam. Clin. Pharmacol., 21, 547-553 (2007).

43) Cetin R., Devrim E., Kiliçoglu B., Avci A., Candir O., Durak I., J. Appl. Toxicol., 26, 42-46 (2006).

44) Weijl N. I., Cleton F. J., Osanto S., Cancer Treat. Rev., 23, 209-240 (1997).

45) Joannidis M., Gstraunthaler G., Pfaller W., Am. J. Physiol., 258, 232236 (1990)

46) Ali M. B., Vajpayee P., Tripathi R. D., Rai U. N., Singh S. N., Singh S. P., Bull. Environ. Contam. Toxicol., 70, 462-469 (2003).

47) Ahn H., Lee E., Kim K., Lee C., J. Urol., 151, 263-267 (1994).

48) Yoshida M., Fukuda A., Hara M., Terada A., Kitanaka Y., Owada S., Life Sci., 72, 1773-1780 (2003).

49) Appenroth D., Fröb S., Kersten L., Splinter F. K., Winnefeld K., Arch Toxicol., 71, 677-683 (1997).

50) Naziroglu M., Karaoglu A., Aksoy A. O., Toxicology, 195, 221-230 (2004).

51) Maliakel D. M., Kagiya T. V., Nair C. K., Exp. Toxicol. Pathol., 60, $521-527$ (2008).

52) Davis C. A., Nick H. S., Agarwal A., J. Am. Soc. Nephrol., 12, 26832690 (2001).

53) Sung M. J., Kim D. H., Jung Y. J., Kang K. P., Lee A. S., Lee S., Kim W., Davaatseren M., Hwang J. T., Kim H. J., Kim M. S., Kwon D. Y., Park S. K., Kidney Int., 74, 1538-1547 (2008).

54) Kang K. P., Kim D. H., Jung Y. J., Lee A. S., Lee S., Lee S. Y., Jang K. Y., Sung M. J., Park S. K., Kim W., Nephrol. Dial. Transplant., 24, $3012-3020(2009)$

55) Li Q., Verma I. M., Nat. Rev. Immunol., 2, 725-734 (2002).

56) Ramesh G., Reeves W. B., J. Clin. Invest., 110, 835-842 (2002).

57) Faubel S., Lewis E. C., Reznikov L., Ljubanovic D., Hoke T. S., Somerset H., Oh D. J., Lu L., Klein C. L., Dinarello C. A., Edelstein C. L., J. Pharmacol. Exp. Ther, 322, 8-15 (2007).

58) Ramesh G., Zhang B., Uematsu S., Akira S., Reeves W. B., Am. J. Physiol. Renal Physiol., 293, F325-F332 (2007).

59) Fouad A. A., Al-Sultan A. I., Refaie S. M., Yacoubi M. T., Toxicology, 274, 49-56 (2010) 